\title{
Core concepts of human rights and vulnerable groups in Nutrition Policy of Sudan
}

\author{
Nafesa Bedri', Mutamad Amin ${ }^{1}$, Amani Elkhatim ${ }^{1}$, Ahmed Gamal Eldin ${ }^{1}$, Malcolm MacLachlan ${ }^{2}$, \\ Hasheem Mannan ${ }^{2}$
}

${ }^{1}$ Ahfad University for Women, Omdurman, Sudan

${ }^{2}$ Centre for Global Health, School of Psychology, Trinity College Dublin, Dublin, Ireland

\section{Email address:}

nmbedri@gmail.com (N. Bedri),mutamadamin@hotmail.com (M. Amin) amai_elkhatim@yahoo.com (A. Elkhatim), ahmedeldin@hotmail.com (A. G. Eldin), malcolm.maclachlan@tcd.ie (M. MacLachlan), mannan@tcd.ie (H. Mannan)

\section{To cite this article:}

Nafesa Bedri,Mutamad Amin,Amani Elkhatim Ahmed Gamal Eldin, Malcolm MacLachlan, Hasheem Mannan. Core Concepts of Human Rights and Vulnerable Groups in Nutrition Policy of Sudan. International Journal of Nutrition and Food Sciences. Vol. 2, No. 6, 2013, pp. 352-359. doi: 10.11648/j.ijnfs.20130206.24

\begin{abstract}
To provide equitable health care, and to realize the United Nations' call for Health for All, health policies have to be committed to core concepts of human rights and be inclusive of vulnerable groups. The aim of this study is to assess the extent to which the Sudan Nutrition Policy addresses core concepts of human rights and the inclusion of vulnerable groups using a novel policy framework (EquiFrame). The overall quality assessment of the policy was Moderate, scoring $67 \%$ for vulnerable groups, $57 \%$ for core concepts of human rights and $29 \%$ for Core Concept Quality. In conclusion, if this policy is to be improved, it is important to integrate the wider notions of human rights within the policy document and link these explicitly to specific and carefully selected vulnerable groups.
\end{abstract}

Keywords: Health Policy Analysis, Human Rights, Vulnerable Groups

\section{Introduction}

The international health movement has promoted the concept of health as a human right, globally, with the Alma Ata Declaration of 'Health for All' in 1978 being followed by calls for greater equity, accessibility and social inclusion over the last three decades [1,2]. Thus, to ensure equal opportunities for accessing health, health policies need to make particular efforts to address those who are disadvantage socially such as poor rural women, children, the aged, ethnic minorities, displaced people, people suffering from illnesses and persons with disabilities [3]. Members of the international nutrition community see international human rights provisions and institutions as a new context in which to develop nutrition policies and programmes [4]. Although access to care is a necessary component of population health, policy action in income security, education, housing, nutrition/food security, and the environment is also critical in efforts to improve health among socially disadvantaged populations [5]. Nutrition plays a major role in human resource development since deficiencies in essential nutrients lead to malnutrition resulting in poor health and poor work performance [6].
Globally one hundred and eighty six million children in the world are estimated to be stunted and 20 million to suffer from the most deadly form of severe acute malnutrition each year. It is the single biggest contributor to child mortality and $15 \%$ of the global burden of new borne and child mortality occurs in countries of the Eastern Mediterranean Region [7]. In Sudan, malnutrition is among the 10 leading causes of death in hospitals [8].

The Nutrition Policy for Sudan document is comprehensive and well written. It consists of a situation analysis followed by two parts; Part A is the Policy which sets out the potential for improved nutrition in Sudan and Part B is the Strategy. Within the Strategy there are three strands: NH being nutrition-in-health strategies, NC being strategies for nutrition across the sectors, and NL being strategies to develop nutrition leadership. One of its main strengths is its insightful and critical analysis of the Sudan context and the main root and immediate causes of malnutrition. The document also underlines the shortcomings of previous attempts to address the problem, arguing strongly that addressing a complex and multifaceted 
problem such as malnutrition cannot be left for the health professionals alone, as it requires adequate coordination and collaboration between a host of government and non-governmental agencies. The policy also underscores the importance of mobilizing adequate resources and using them efficiently and responsibly. The policy also acknowledges the enormity of the task of tackling malnutrition in Sudan and hence sets priorities and divides the implementation of the policy into three interconnected phases: the short-term (2006-2007) and medium-term priories (2008-2010) to be addressed by the introduced policy; and the long-term phase that builds on the first two phases and extends from 2011 onwards. The main thrust of the nutrition policy is defined as coordination, partnership and increased resources.

The main general weakness of the policy is that it gives more emphasis to health rather than nutrition, and therefore consolidates the misperception of malnutrition as a health problem. Moreover, in its context analysis section, the policy outlines shortcomings in past experiences pertinent to addressing the problem of malnutrition and describes situations and challenges but fails to adequately address them in the main body of the policy and its implementation strategies.

This paper reports on the application of EquiFrame, a novel policy analysis framework, to the Sudan Nutrition Policy. An internationally peer-reviewed framework, based on best practices principles of systematic review, EquiFrame evaluates the degree of explicit commitment of a health policy to 21 Core Concepts of human rights and to 12 Vulnerable Groups, guided by the ethos of universal, equitable and accessible health services. In its current form, it is directed towards health policy-oriented researchers and policy-makers. The Framework has been applied in the analysis of 51 health policies across Namibia, Malawi, South Africa, and Sudan, highlighting some very strong health policies, serious shortcomings in other policies, as well as country-specific patterns. Health policies were included if they met the following criteria: (1) Health policy documents produced by the Ministry of Health; (2) Policies addressing health issues outside of the Ministry of Health; (3) Strategies that address health policies; and (4) Policies related to the top 10 health conditions identified by the
World Health Organization (WHO) within the respective country. In the Sudanese context, 16 health policies were identified and analyzed, inclusive of the Sudan Nutrition Policy. Partly due to Sudan's food insecurity, the nutrition situation in Sudan is very poor, and is characterized by high levels of underweight and chronic malnutrition and continually elevated levels of acute malnutrition [9]. In the Sudanese context, vulnerable groups include, among others, children, youth, internally-displaced populations, refugees, some ethnic minorities, and people with disabilities [9]. The aim of this study is to assess the extent to which the Sudan Nutrition Policy addresses Core Concepts of human rights and the inclusion of Vulnerable Groups.

\section{Development of EquiFrame}

There is a paucity of literature that outlines and utilises analytical frameworks for the actual content of policies, or policy 'on the books' [10]. There is, however, a body of research on the process of health policy development [11]. While this body of research focuses on the critical importance of how policy is made, very little guidance is offered on evaluating the actual content of policies, or policy 'on the books'. The focus of the present research was to develop and apply a method for analyzing the content of policies. EquiFrame has been devised with the intention of developing a health policy analysis framework that would be of particular relevance in low-income countries in general, and in Africa in particular. It is guided by the ethos of universal, equitable and accessible health services. EquiFrame has been developed as part of a Work Package led by Ahfad University for Women, Sudan, within a larger EU FP7 funded project, EquitAble, which is led by the Centre for Global Health at Trinity College, Dublin, and which has a consortium of international partners (see www.equitableproject.org).

\section{The Framework}

EquiFrame's 21 Core Concepts are presented alongside a series of key questions and key language, each series tailored to elucidate the specified Core Concept (see Table 1).

Table 1. EquiFrame Core Concepts of Human Rights; and Key Questions Key Language

\begin{tabular}{|c|c|c|c|}
\hline No. & Core Concept & Key Question & Key Language \\
\hline 1. & Non-discrimination & $\begin{array}{l}\text { Does the policy support the rights of vulnerable } \\
\text { groups with equal opportunity in receiving health } \\
\text { care? }\end{array}$ & $\begin{array}{l}\text { Vulnerable groups are not discriminated against on the } \\
\text { basis of their distinguishing characteristics (i.e. Living } \\
\text { away from services; Persons with disabilities; Ethnic } \\
\text { minority or Aged). }\end{array}$ \\
\hline 2. & Individualised Services & $\begin{array}{l}\text { Does the policy support the rights of vulnerable } \\
\text { groups with individually tailored services to meet } \\
\text { their needs and choices? }\end{array}$ & $\begin{array}{l}\text { Vulnerable groups receive appropriate, effective, and } \\
\text { understandable services. }\end{array}$ \\
\hline 3. & Entitlement & $\begin{array}{l}\text { Does the policy indicate how vulnerable groups may } \\
\text { qualify for specific benefits relevant to them? }\end{array}$ & $\begin{array}{l}\text { People with limited resources are entitled to some } \\
\text { services free of charge or persons with disabilities may } \\
\text { be entitled to respite grant. }\end{array}$ \\
\hline 4. & $\begin{array}{l}\text { Capability- } \\
\text { Services }\end{array}$ & $\begin{array}{l}\text { Does the policy recognise the capabilities existing } \\
\text { within vulnerable groups? }\end{array}$ & $\begin{array}{l}\text { For instance, peer to peer support among women headed } \\
\text { households or shared cultural values among ethnic } \\
\text { minorities. }\end{array}$ \\
\hline
\end{tabular}




\begin{tabular}{|c|c|c|c|}
\hline No. & Core Concept & Key Question & Key Language \\
\hline 5. & Participation & $\begin{array}{l}\text { Does the policy support the right of vulnerable } \\
\text { groups to participate in the decisions that affect their } \\
\text { lives and enhance their empowerment? }\end{array}$ & $\begin{array}{l}\text { Vulnerable groups can exercise choices and influence } \\
\text { decisions affecting their life. Such consultation may } \\
\text { include planning, development, implementation, and } \\
\text { evaluation. }\end{array}$ \\
\hline 6. & Coordination of Services & $\begin{array}{l}\text { Does the policy support assistance of vulnerable } \\
\text { groups in accessing services from within a single } \\
\text { provider system (inter-agency) or more than one } \\
\text { provider system (intra-agency) or more than one } \\
\text { sector (inter-sectoral)? }\end{array}$ & $\begin{array}{l}\text { Vulnerable groups know how services should interact } \\
\text { where inter-agency, intra-agency, and inter-sectoral } \\
\text { collaboration is required. }\end{array}$ \\
\hline 7. & Protection from Harm & $\begin{array}{l}\text { Are vulnerable groups protected from harm during } \\
\text { their interaction with health and related systems? }\end{array}$ & $\begin{array}{l}\text { Vulnerable groups are protected from harm during their } \\
\text { interaction with health and related systems. }\end{array}$ \\
\hline 8. & Liberty & $\begin{array}{l}\text { Does the policy support the right of vulnerable } \\
\text { groups to be free from unwarranted physical or other } \\
\text { confinement? }\end{array}$ & $\begin{array}{l}\text { Vulnerable groups are protected from unwarranted } \\
\text { physical or other confinement while in the custody of the } \\
\text { service system/provider. }\end{array}$ \\
\hline 9. & Autonomy & $\begin{array}{l}\text { Does the policy support the right of vulnerable } \\
\text { groups to consent, refuse to consent, withdraw } \\
\text { consent, or otherwise control or exercise choice or } \\
\text { control over what happens to him or her? }\end{array}$ & $\begin{array}{l}\text { Vulnerable groups can express "independence" or } \\
\text { "self-determination". For instance, person with an } \\
\text { intellectual disability will have recourse to an } \\
\text { independent third party regarding issues of consent and } \\
\text { choice. }\end{array}$ \\
\hline 10. & Privacy & $\begin{array}{l}\text { Does the policy address the need for information } \\
\text { regarding vulnerable groups to be kept private and } \\
\text { confidential? }\end{array}$ & $\begin{array}{l}\text { Information regarding vulnerable groups need not be } \\
\text { shared among others. }\end{array}$ \\
\hline 11. & Integration & $\begin{array}{l}\text { Does the policy promote the use of mainstream } \\
\text { services by vulnerable groups? }\end{array}$ & $\begin{array}{l}\text { Vulnerable groups are not barred from participation in } \\
\text { services that are provided for general population. }\end{array}$ \\
\hline 12. & Contribution & $\begin{array}{l}\text { Does the policy recognise that vulnerable groups can } \\
\text { be productive contributors to society? }\end{array}$ & $\begin{array}{l}\text { Vulnerable groups make a meaningful contribution to } \\
\text { society. }\end{array}$ \\
\hline 13. & Family Resource & $\begin{array}{l}\text { Does the policy recognise the value of the family } \\
\text { members of vulnerable groups in addressing health } \\
\text { needs? }\end{array}$ & $\begin{array}{l}\text { The policy recognises the value of family members of } \\
\text { vulnerable groups as a resource for addressing health } \\
\text { needs. }\end{array}$ \\
\hline 14. & Family Support & $\begin{array}{l}\text { Does the policy recognise individual members of } \\
\text { vulnerable groups may have an impact on the family } \\
\text { members requiring additional support from health } \\
\text { services? }\end{array}$ & $\begin{array}{l}\text { Persons with chronic illness may have mental health } \\
\text { effects on other family members, such that these family } \\
\text { members themselves require support. }\end{array}$ \\
\hline 15. & Cultural Responsiveness & $\begin{array}{l}\text { Does the policy ensure that services respond to the } \\
\text { beliefs, values, gender, interpersonal styles, } \\
\text { attitudes, cultural, ethnic, or linguistic aspects of the } \\
\text { person? }\end{array}$ & $\begin{array}{l}\text { i) Vulnerable groups are consulted on the acceptability of } \\
\text { the service provided. } \\
\text { ii) Health facilities, goods and services must be respectful } \\
\text { of ethical principles and culturally appropriate, i.e., } \\
\text { respectful of the culture of vulnerable groups. }\end{array}$ \\
\hline 16. & Accountability & $\begin{array}{l}\text { Does the policy specify to whom, and for what, } \\
\text { services providers are accountable? }\end{array}$ & $\begin{array}{l}\text { Vulnerable groups have access to internal and } \\
\text { independent professional evaluation or procedural } \\
\text { safeguard. }\end{array}$ \\
\hline 17. & Prevention & $\begin{array}{l}\text { Does the policy support vulnerable groups in } \\
\text { seeking primary, secondary, and tertiary prevention } \\
\text { of health conditions? }\end{array}$ & \\
\hline 18. & Capacity Building & $\begin{array}{l}\text { Does the policy support the capacity building of } \\
\text { health workers and of the system that they work in } \\
\text { addressing health needs of vulnerable groups? }\end{array}$ & \\
\hline 19. & Access & $\begin{array}{l}\text { Does the policy support vulnerable groups - } \\
\text { physical, economic, and information access to health } \\
\text { services? }\end{array}$ & $\begin{array}{l}\text { Vulnerable groups have accessible health facilities (i.e., } \\
\text { transportation; physical structure of the facilities; } \\
\text { affordability and understandable information in } \\
\text { appropriate format). }\end{array}$ \\
\hline 20. & Quality & $\begin{array}{l}\text { Does the policy support quality services to } \\
\text { vulnerable groups through highlighting the need for } \\
\text { evidence-based and professionally skilled practice? }\end{array}$ & $\begin{array}{l}\text { Vulnerable groups are assured of the quality of the } \\
\text { clinically appropriate services. }\end{array}$ \\
\hline 21. & Efficiency & $\begin{array}{l}\text { Does the policy support efficiency by providing a } \\
\text { structured way of matching health system resources } \\
\text { with service demands in addressing health needs of } \\
\text { vulnerable groups? }\end{array}$ & \\
\hline
\end{tabular}


These 21 Core Concepts represent a broad range of salient concerns in striving for equitable, accessible and universal healthcare. 'Core Concept' may be interpreted as a 'central, often foundational policy component generalised from particular instances (namely, literature reviews, analyses of statutes and judicial opinions, and data from focus groups and interviews)' [12].

Vulnerable Groups may be defined as 'social groups who experience limited resources and consequent high relative risk for morbidity and premature mortality' [13], and may included children, the aged, ethnic minorities, displaced populations, people suffering from chronic illnesses, and persons with disabilities. Importantly, Eichler and Burke [14] have recognised that the social discrimination and bias that arise based on such categories are the result of social hierarchies: similar exclusionary practices disempower and disadvantage different groups, undermining their human rights and their rights to health, other social services, and to social inclusion - to being full participants in society.

The World Report on Disability [15] estimates that over one billion people, or approximately $15 \%$ of the world's population, are living with disability; yet many people with disabilities do not have equal access to healthcare, education, and employment opportunities, do not receive the disability-related services that they need, and encounter exclusion from everyday activities [15]. Accordingly, a particular interest of the research team was to assess the degree to which persons with disabilities (identified by EquiFrame as a Vulnerable Group) were incorporated in policy documents for the purpose of promoting more accessible healthcare. Definitions for Vulnerable Groups are provided in Table 2 .

Table 2: EquiFrame Vulnerable Groups Definitions

\begin{tabular}{|c|c|c|}
\hline No. & Vulnerable Group & Attributes or Definitions \\
\hline 1. & Limited Resources & Referring to poor people or people living in poverty \\
\hline 2. & Increased Relative Risk For Morbidity & $\begin{array}{l}\text { Referring to people with one of the top } 10 \text { illnesses, identified by WHO, as occurring within the } \\
\text { relevant country }\end{array}$ \\
\hline 3. & Mother Child Mortality & Referring to factors affecting maternal and child health ( $0-5$ years) \\
\hline 4. & Women Headed Household & Referring to households headed by a woman \\
\hline 5. & Children (with special needs) & Referring to children marginalised by special contexts, such as orphans or street children \\
\hline 6. & Aged & Referring to older age \\
\hline 7. & Youth & Referring to younger age without identifying gender \\
\hline 8. & Ethnic Minorities & Referring to non-majority groups in terms of culture, race or ethnic identity \\
\hline 9. & Displaced Populations & $\begin{array}{l}\text { Referring to people who, because of civil unrest or unsustainable livelihoods, have been } \\
\text { displaced from their previous residence }\end{array}$ \\
\hline 10. & Living Away from Services & Referring to people living far from health services, either in time or distance \\
\hline 11. & Suffering from Chronic Illness & Referring to people who have an illness which requires continuing need for care \\
\hline 12. & Disabled & $\begin{array}{l}\text { Referring to persons with disabilities, including physical, sensory, intellectual or mental health } \\
\text { conditions, and including synonyms of disability }\end{array}$ \\
\hline
\end{tabular}

EquiFrame has been devised with the aim of generating a systematic evaluative and comparative analysis of health policies on technical content and design. The Framework has been presented at a workshop conducted for the Ministry of Health in Malawi, comprising senior policy-makers [16], and has provided guidance in the redrafting of the Malawian National Health Policy. The utility of EquiFrame, therefore, extends beyond that of a tool for the evaluation of policies, to the promotion of equity, human rights and inclusion in the revision of existing policies and the development of new policies. For further details specific to EquiFrame and the process of its formulation, including a more detailed discussion of literature sources for Core Concepts and Vulnerable Groups, readers are referred to the EquiFrame manual [17; please see also 3,18-22].

\section{Method}

\subsection{Summary Indices}

The four summary indices of EquiFrame are outlined below:
(1) Core Concept Coverage: A policy was examined with respect to the number of Core Concepts mentioned, from among the 21 Core Concepts identified; and this ratio was expressed as a rounded-up percentage. In addition, the actual terminologies used to explain the Core Concepts within each document were extracted, to allow for future qualitative analysis and cross-checking between raters [3,17-22].

(2) Vulnerable Group Coverage: A policy was examined with respect to the number of Vulnerable Groups mentioned, from among the 12 Vulnerable Groups identified; and this ratio was expressed as a rounded-up percentage. In addition, the actual terminologies used to describe the Vulnerable Groups were extracted, to allow for qualitative analysis and cross-checking between raters.

(3) Core Concept Quality: A policy was examined with respect to the number of Core Concepts within it that were rated as 3 or 4 (as either stating a specific policy action to address a Concept or an intention to 
monitor a Concept) out of the 21 Core Concepts identified; and this ratio was expressed as a rounded-up percentage. When several references to a Core Concept were found, the top quality score received was recorded as the final quality scoring for the respective Concept.

(4) Each document was given an Overall Summary Ranking in terms of it being of High, Moderate or Low standing according to the following criteria:

(i) High $=$ if the policy achieved $\geq 50 \%$ on all of the three scores above.

(ii) Moderate $=$ if the policy achieved $\geq 50 \%$ on two of the three scores above.

(iii) Low $=$ if the policy achieved $<50 \%$ on two or three of the three scores above.

\subsection{Scoring}

Each Core Concept received a score on a continuum from 1 to 4 . This was a rating of the quality of commitment to the Core Concept within the policy document:

$1=$ Core Concept only mentioned.

$2=$ Core Concept mentioned and explained.

$3=$ Specific policy actions identified to address the Core Concept.

$4=$ Intention to monitor the Core Concept expressed.

If a Core Concept was not relevant to the document context, it was stated as not applicable.

Each policy document was assessed by two independent raters. For each document, the presence of Core Concepts was assessed for each Vulnerable Group that was identified in the policy. If no Vulnerable Group was mentioned but a Core Concept addressed the total population (e.g. 'all people'), the Core Concept was scored as 'Universal'. The total number and scores for mentioned Core Concepts and Vulnerable Groups was calculated for each document across the four countries; South Africa, Malawi, Namibia and Sudan.

\section{Results}

The Sudan Nutrition Policy scored 67\% for Vulnerable Group Coverage; $57 \%$ for Core Concept Coverage; and 29\% for Core Concept Quality. The policy document therefore received an Overall Summary Ranking of Moderate quality.

\subsection{Inclusion of Core Concepts}

Our critical examination of the policy document on the basis of the methodology outlined above reveals that 9 out of 21 Core Concepts were not mentioned in the document with reference to Vulnerable Groups. This represents some (43\%) of the total Core Concepts, including Non-discrimination, Entitlement, Coordination of services, Liberty, Autonomy, Privacy, Integration, Accountability, and Quality. The most frequently occurring Core Concepts are Capacity building (cited 9 times), Protection from harm and Prevention (each cited 6 times).

\subsection{Vulnerable Groups in the Nutrition Policy}

The most frequently occurring Vulnerable Group in the policy document was Mother Child Mortality (cited 23 times), followed by Limited resources (cited 7 times), Increased relative risk for morbidity, and Youth (each cited 6 times). The policy did not explicitly mention the following Vulnerable Groups: Women headed household, Children (with special needs), Ethnic minorities, and Disabled. . Noteworthy is the mentioning of a number of Core Concepts within the policy without reference to any specific Vulnerable Group. Accordingly, these Core Concepts were scored as 'Universal' (cited 25 times).

\subsection{Core Concept Quality}

Six Core Concepts were scored as 3 or 4 . These were: Protection from harm, Cultural responsiveness, Family resource, Family support, Capacity building, and Efficiency.

\section{Discussion}

The analysis of the Sudan Nutrition Policy shows wide variations in addressing both core concepts of human rights and vulnerable groups in the country. The notion of universality of the population is very dominant in the policy document. For instance, the vision of this policy reads as follows: "Commitment to promoting nutritional well-being for all our people becomes an integral part of all humanitarian and development policies, plans and effective programs in Sudan". Moreover, terms such as "the entire population", the "whole population", the "population of all ages" is frequently mentioned in the policy. Attempting to include "all people" at "all age groups" can be problematic or even crippling for such policies within the current context of Sudan. Adequate nutrition is, and should be, a matter of concern with regard to the whole population. However, in a country with a widespread and chronic malnutrition problem in a context of coexisting food abundance and resources scarcity, such as in the case of Sudan, it is imperative for any nutrition policy to be more specific, selective and targeted. It is true that malnutrition is a wide-spread problem that affects many sections of the Sudanese society, but it does not affect people at random or equally. It has been reported that those who are more affluent suffer less from malnutrition and in areas with widespread poverty, vulnerable groups are unable to secure adequate food intake even when food is in abundance [23]. Given the limited resources available and the competing demands and interests, one therefore expects such a health policy to be strong in its adoption of core concepts pertinent to human rights of the vulnerable members of the society who, for socioeconomic and political reasons, often fail to access the adequate quantities, of sufficient quality, of food.

The concept of nutrition as a human rights issue and as a matter of social justice is not evident in the document. Instead, the document tends to emphasize the functionality of good nutrition (e.g. productivity and development) and 
the treatment of malnutrition as a health problem. The policy document is also not very clear on its use of the concept of Efficiency. Efficiency was largely used to refer to efficient use of financial resources rather than the efficiency of the intervention to address the malnutrition of specific group/s of people. The most frequently occurring Core Concepts in the document were Protection from harm, Prevention and Capacity building. Yet all three concepts scored low frequencies. It is surprising that the most fundamental concept of human rights, Non-discrimination [4,24], although cited many times throughout the document, was mentioned without reference to any Vulnerable Group.

Although many Core Concepts were included in the document, their inclusion was not adequate enough to ensure their commitment to specific Vulnerable Groups. For example, the Core Concept of Protection from harm is widely mentioned, but it was not well-explained in relation to the protection of whom and from what harm specifically. Similarly, the Core Concept of Prevention was mentioned several times; yet despite the importance of adequate food intake for good nutrition, it was not related to prevention from hunger. This reflects one of the main shortcomings of this policy, which emphasizes malnutrition as a health problem concerning children and their mothers, and thus contends with nutrition more curatively than preventively. Also, the Core Concept of Integration was highlighted in conjunction with the Core Concept of Coordination, but the implementation strategy failed to operationalise it and make it a central component of the intervention.

The important Core Concept of Privacy was not mentioned in the policy document. However, this is not surprising as this notion of privacy has never been addressed systematically in the Sudanese health system, often assigned to the individual judgment of the professional, or internal professional misconduct regulations. Indeed, Aldersey and Turnbull [25], analyzing Tanzania's National Policy on Disability, reported that cultural relativists would caution against automatically translating Western values of rights, such as privacy, to a non-Western context without exploring the suitability of doing so within the specific cultural context The Core Concepts of Liberty and Non-discrimination were also important but generally not addressed in the policy document. The exclusion of important concepts such as Accountability and Quality in this policy document is a shortcoming that can have a wider impact, as it will be difficult for the Sudanese health system to be efficient without these two concepts.

With regards to Vulnerable Group Coverage, Sudan is a multiethnic and multicultural country with hundreds of ethnic and tribal divisions and languages [26]. Even so, there was no attempt to address the plight of Ethnic minorities as one of the vulnerable groups in the country. One explanation for this shortcoming of the document is the ethnic politics of the country, in which there is no consensus on what constitutes ethnic minorities and majorities in the country. This renders ethnicity a very sensitive matter. It is not surprising, therefore, that Ethnic minorities was never mentioned in the document, which instead referred to internally-displaced persons (IDPs), especially those living in official camps. Sudan is a country heavily hit by natural and manmade disasters that have a devastating impact on the nutritional status of the Sudanese population, resulting in displacement of the population and poverty. In Sudan, IDPs are estimated at 5.35 million throughout the country in 2006 [27]. In December 2010, a total of between 4.5 and 5.2 million IDPs were believed to be displaced in the Western Region of Darfur, in and around Khartoum State, in Southern Kordofan State, and in Southern Sudan. The problems facing IDPs include housing, food, clean water, clothes, children's education, adequate healthcare, and the right to a stable place, It is therefore important to address this group (Displaced populations) in a fundamental way. However, urban poor in squatter settlements and IDPs living outside of official camps in Sudan are often worse-off compared to IDPs living inside of official camps, as the latter tend to receive more attention and services such as supplementary and therapeutic feeding (often provided by international aid agencies).

Around 15 per cent of the world's population, or over one billion people, live with a disability [15]. They are the world's largest minority [27]. The Sudanese National Policy for Disability defines disability as "individuals who are affected by functional disability being motor, sensory or mentally, occurring from birth or as a result of an accident which permanently or partially affected individual's natural/ normal life pattern" [21]. In Sudan, people with disabilities have poorer health outcomes, lower educational achievements, less economic participation, and higher rates of poverty than those without disabilities [9]. The Nutrition Policy ignored the group Disabled though they are the poorest of the poor. Emmett and Alant [28] reported that women with disabilities in South Africa are more discriminated against and disadvantaged than men with disabilities. Poverty and deprivation magnify these inequalities and can determine access to food, care and social inclusion, and can even threaten survival. Similar findings were reported for people with disabilities in rural north Namibia and Sir Lanka [29,30]. Therefore, it is imperative for the nutrition policy to approach malnutrition as one of the manifestations of poverty, which is also associated with the distribution of wealth and political power, rather than as a separate and isolated health related phenomenon. The vulnerable group of Limited Resources could have been better addressed in the Sudan Nutrition Policy. Finally, it is important to emphasise that the Sudan Nutrition Policy did not explicitly mention the Vulnerable Group of Women headed household. As affirmed by the United Nations [9], food deprivation in Sudan in 2012 was higher in female-headed households ( 37 percent) than in male-headed households (31 percent), conceivably explained by better access on average of male-headed households to education, employment, and a higher income; female headed-households require special support.

In conclusion, even when Core Concepts were explicitly mentioned in this document, the notion of vulnerability was not fundamental or well-integrated. As affirmed by the 
United Nations [9], in the context of food insecurity and malnutrition in Sudan, social groups including the elderly poor, internally-displaced persons, people suffering from illness, and those living in extreme poverty are evidently at risk. Therefore, if this policy is to be improved and made more relevant to the context of malnutrition in Sudan, it is important to strengthen the notion of nutrition as a human rights issue and to integrate the wider notions of human rights within the policy document and link these explicitly to specific and carefully selected vulnerable groups, as these social groups are either exclusively or predominantly affected by the problem of malnutrition in the country.

We declare that we have no conflicts of interest.

\section{Acknowledgements}

This research was funded by the European Commission Framework Programme 7, Project Title: Enabling Universal and Equitable Access to Healthcare for Vulnerable People in Resource Poor Settings in Africa, Grant Agreement No.: 223501.

\section{References}

[1] Declaration of Alma-Ata, International Conference on Primary Health Care, Alma-Ata, USSR, 6-12 September, 1978

(http://www.who.int/publications/almaata_declaration_en.pd f, accessed 13 April 2013).

[2] World Health Organization. Health \& Human Rights. Geneva, World Health Organization, n.d. (http://www.who.int/hhr/teamflyer_eng_rev.pdf, accessed 13 April 2013).

[3] MacLachlan M et al. Inclusion and human rights in health policies: Comparative and benchmarking analysis of 51 policies from Malawi, Sudan, South Africa and Namibia. PLoS ONE, 2012, 7(5):e35864. doi:10.1371/journal.pone. 0035864

[4] Eide WB. Nutrition and human rights. In: United Nations (Administrative Committee on Coordination Sub-Committee on Nutrition), editors. Nutrition: A foundation for development (Geneva: ACC/SCN, 2002) (http://www.ifpri.org/sites/default/files/publications/intnut.p df, accessed 13 April 2013).

[5] Lantz PM, Lichtenstein RL, Pollack HA. Health policy approaches to population health: The limits of medicalization. Health Affairs, 2007;26(5):1253-7.

[6] Sharkey JR. Diet and health outcomes in vulnerable populations. Annals of the New York Academy of Sciences, 2008; 1136(1):210-7.

[7] World Health Organization (Regional Office for the Eastern Mediterranean). Regional strategy on nutrition 2010-2019 and plan of action. Cairo, World Health Organization, 2011 (http://applications.emro.who.int/dsaf/dsa1230.pdf, accessed 13 April 2013).

[8] National Ministry of Health. Annual Health Statistical Report. National Health Information Centre, Sudan. Sudan Currency
Printing press, 2009.

[9] United Nations Country Team in the Republic of Sudan. Country Analysis 2012. Khartoum, United Nations, 2012 (http://www.undg.org/docs/12642/201202_SUD-Country-A nalysis.pdf, accessed 15 April 2013).

[10] Stowe MJ, Turnbull HR. Tools for analysing policy "on the books" and policy "on the streets". Journal of Disability Policy Studies, 2001, 12(3):206-14.

[11] Gilson L et al. Future directions for health policy analysis: A tribute to the work of professor Gill Walt. Health Policy \& Planning, 2008, 23(5):291-93.

[12] Umbarger GT, Stowe MJ, Turnbull HR. The core concepts of health policy affecting families who have children with disabilities. Journal of Disability Policy Studies, 2005, 15(4):201-208. DOI: 10.1177/10442073050150040201

[13] Flaskerud JH, Winslow BJ. Conceptualising vulnerable populations health-related research. Nursing Research, 1998, 47(2):69-78.

[14] Eichler M, Burke MA. The BIAS FREE framework: A new analytical tool for global health research. Canadian Journal of Public Health, 2006, 97(1):63-68.

[15] World Health Organization, World Bank. World report on disability. Geneva, World Health Organization, 2011 (http://whqlibdoc.who.int/publications/2011/978924068521 5 eng.pdf, accessed 13 April 2013).

[16] Munthali A, Mannan H, MacLachlan M. Social inclusion and health policies. National workshop for health policy-makers and policy-analysts. Lilongwe, Malawi, 8-9 Nov, 2011.

[17] Mannan $\mathrm{H}$ et al. The EquiFrame manual: A tool for evaluating and promoting the inclusion of vulnerable groups and core concepts of human rights in health policy documents. Dublin, Global Health Press, 2011.

[18] Mannan $\mathrm{H}$ et al. Core concepts of human rights and inclusion of vulnerable groups in the mental health policies of Malawi, Namibia, and Sudan. International Journal of Mental Health Systems, 2013, 7(7). doi:10.1186/1752-4458-7-7

[19] Mannan $\mathrm{H}$ et al. Non-communicable disease priority actions and social inclusion. Lancet, 2012, 379(9812):17-18.

[20] Mannan $\mathrm{H}$ et al. Core concepts of human rights and inclusion of vulnerable groups in the United Nations Convention on the Rights of Persons with Disabilities. ALTER - European Journal of Disability Research, 2012, 6(3).

[21] Mannan $\mathrm{H}$ et al. Core concepts of human rights and inclusion of vulnerable groups in the disability and rehabilitation policies of Malawi, Namibia, Sudan and South Africa. Journal of Disability Policy Studies, 2012, 23(2):67-81.

[22] Amin M et al. EquiFrame: A framework for analysis of the inclusion of human rights and vulnerable groups in health policies. Health \& Human Rights: An International Journal, 2011, 13(2).

[23] Van de Poel E et al. Socioeconomic inequality in malnutrition in developing countries. Bulletin of the World Health Organization

(http://www.who.int/bulletin/volumes/86/4/07-044800/en/, accessed 15 April 2013). 
[24] Hunt P, Backman G. Health systems and the right to the highest attainable standard of health. Health \& Human Rights, 2008, 10:81-92.

[25] Aldersey HM, Turnbull HR. The United Republic of Tanzania's National Policy on Disability: A policy analysis. Journal of Disability Policy Studies, 2011, 20:1-10.

[26] Ismail E. Culture and Society in the Sudan - People and Ethnicity (www.ellen-ismail .de/impression2engl.htm, accessed 15 April 2013).

[27] Internal Displacement Monitoring Centre. (http://www.internal-displacement.org/8025708F004CE90B /\%28httpCountries\%29/F3D3CAA7CBEBE276802570A70 04B87E4?opendocument\&count $=10000$, accessed 15 April 2013).
[28] Emmett T, Alant E. Women and disability: Exploring the interface of multiple disadvantages. Development Southern Africa, 2006, 23(4):445-60. 29. Van Rooy G et al. Perceived barriers to accessing health services among people with disabilities in rural northern Namibia. Disability and Society, 2012, 27(6):761-775.

[29] Russell S, Gilson L. Are health services protecting the livelihoods of the urban poor in Sri Lanka? Findings from two low-income areas of Colombo. Soc Sci Med, 2006, 63(7):1732-44 